\title{
The age of paraffin block influences biomarker levels in archival breast cancer samples
}

\author{
HONG CHEN ${ }^{1}$, QING-QING FANG ${ }^{2}$ and BO WANG ${ }^{3}$ \\ ${ }^{1}$ Department of Stomatology, Zhejiang Provincial People's Hospital (People's Hospital of Hangzhou Medical College), \\ Hangzhou, Zhejiang 310014; ${ }^{2}$ Department of Plastic Surgery, Sir Run Run Shaw Hospital, College of Medicine, \\ Zhejiang University, Hangzhou, Zhejiang 310016; ${ }^{3}$ Department of Pathology, The First Affiliated Hospital, \\ College of Medicine, Zhejiang University, Hangzhou, Zhejiang 310003, P.R. China
}

Received August 12, 2019; Accepted February 7, 2020

DOI: $10.3892 / 01.2020 .11586$

\begin{abstract}
The present study aimed to investigate the influence of paraffin block age on biomarker levels in archival breast cancer samples. Tissue blocks from five different block age groups were assessed using immunohistochemistry and fluorescence in situ hybridization. The difference in Q scores for estrogen receptor and progesterone receptor expression levels between original tests and repeated tests were significant for core needle biopsies prepared 10 years ago. The signal intensities of human epidermal growth factor receptor 2 and the centromere of chromosome 17 decreased with the age of the paraffin block. Moreover, 6 samples exhibited a negative shift in progesterone receptor $\mathrm{Q}$ scores for core needle biopsy samples with a $\mathrm{Q}$ score of 2 . In conclusion, the age of paraffin blocks had significant effects on the expression levels of estrogen and progesterone receptors in core needle biopsies prepared 10 years ago. The results showed that samples with an age $>7$ years were not suitable for fluorescence in situ hybridization and interpretation of progesterone receptor levels for repeated core needle biopsy samples with a $\mathrm{Q}$ score of 2 requires caution.
\end{abstract}

\section{Introduction}

According to the global cancer statistics in 2011, breast cancer is the most commonly diagnosed carcinoma and the second leading cause of cancer-associated death among women in China (1). Clinically, all invasive primary breast cancer cases are analyzed for the expression levels of estrogen receptor (ER), progesterone receptor (PR) and human epidermal grow th factor receptor 2 (HER2) (2). Correct measurement

Correspondence to: Dr Bo Wang, Department of Pathology, The First Affiliated Hospital, College of Medicine, Zhejiang University, 79 Qingchun Road, Hangzhou, Zhejiang 310003, P.R. China E-mail: 1506128@zju.edu.cn

Key words: paraffin block, estrogen receptor, progesterone receptor, human epidermal growth factor receptor 2 of these receptors is essential for accurate therapeutic decision-making (3-5).

Immunohistochemistry (IHC) is recommended for the detection of ER and PR (6). There are two commonly used methods for evaluating HER2 status, including IHC to determine the expression levels of the HER2 protein and fluorescence in situ hybridization (FISH) for the detection of HER2 gene amplification (7). Several studies have considered pre-analytic factors, for example the effect of cold ischemic time, on the level of biomarkers in archival breast cancer tissue (2,8-10). However, few studies have considered the association between the age of the paraffin block and the levels of ER, PR and HER2.

Given the differences in the testing methods and reagents, problem can arise between local and centralized HER2 testing in laboratories. It has been reported that HER 2 testing is more accurate when performed at high-volume central laboratories and results can be quite different between local community-based laboratories and central laboratories (11). In routine practice, breast cancer cases are often presented to the Department of Pathology, The First Affiliated Hospital of Zhejiang University (Hangzhou, China) for consultation, of which some cases were diagnosed $>5$ years ago. Since there is variability among central and local laboratories, repeated tests are often required to determine the ER, PR and HER 2 levels. Importantly, it is not clear whether biomarkers are altered in cancer tissues that have been stored for long periods of time.

To address the association between the age of paraffin blocks and the expression levels of ER, PR and HER2, the present study compared ER and PR levels between repeated tests and the original tests. Since the original fluorescence in situ hybridization (FISH) tests often lacked signal intensity, HER2 and chromosome enumeration probe 17 (CEP17) were assessed for different age groups.

\section{Materials and methods}

Specimen collection. A total of 100 patients (median age, 56.7 years; age range, 31-85 years) were recruited between January 2007 and December 2017. The criteria for the recruitment of samples were as follows: i) Patients did not receive neoadjuvant chemotherapy; ii) samples were processed on 
working days, but not on weekends or holidays to ensure procedural consistency; and iii) cases had been tested for the expression levels of ER and PR using IHC, and HER2 gene amplification using FISH. Tissue blocks were collected according to the following 5 age groups: 1 year ago, defined as new paraffin blocks (12); 3 years ago; 5 years ago; 7 years ago; and 10 years ago. In each group, 10 mastectomy cases and 10 core needle biopsy cases were selected. Due to limited tissues, a total of 18 cases were not assessed using IHC or FISH. The final number of samples included in the study is shown in (Table I). All the samples were fixed in $10 \%$ neutral-buffered formalin (http://nbtssw.com) at room temperature for 6-24 h. The present study was approved by The Ethics Committee of the First Affiliated Hospital, College of Medicine, Zhejiang University (Hangzhou, China). The Committee waived the need for informed consent from the patients because the study was completed anonymously.

$I H C$. Sections were cut at $4 \mu \mathrm{m}$, placed on positively charged slides and dried overnight at $65^{\circ} \mathrm{C}$. The slides were deparaffinized in xylene at room temperature (RT) and dehydrated in 75, 85 and 100\% alcohol. Endogenous peroxidase activity was inhibited by incubating the slides in $3 \% \mathrm{H}_{2} \mathrm{O}_{2}$ for $10 \mathrm{~min}$ at RT. Nonspecific binding sites were blocked with 10\% normal goat serum (Beijing Zhongshan Jinqiao Biotechnology Co., Ltd.) at $37^{\circ} \mathrm{C}$ for $10 \mathrm{~min}$. Sections were then incubated with anti-ER (1:200; cat. no. ab16660; Clone SP1; Abcam) and anti-PR (1:150; cat. no. M356929; Dako; Agilent Technologies, Inc.) in humid chambers for $1 \mathrm{~h}$ at $37^{\circ} \mathrm{C}$. The sections were rinsed three times with PBS and then incubated with a secondary antibody, Dako Real Envision /HRP, Rabbit/Mouse (ready-to-use; cat. no. K5007; Dako; Agilent Technologies, Inc.) for $30 \mathrm{~min}$ at RT. DAB (Dako; Agilent Technologies, Inc) was applied for $\sim 2 \mathrm{~min}$ at RT and removed by rinsing with distilled water. Slides were counterstained with hematoxylin for $30 \mathrm{sec}$ at RT.

Staining of ER and PR was assessed semi-quantitatively by using Q-scoring, which incorporates intensity and distribution of reactivity $(8,13)$. Intensity was scored as follows: 0 , negative (no staining of any nuclei at high magnification); 1 , weak (staining visible only at high magnification); 2 , moderate (staining readily visible at low magnification); or 3 , strong (clear positive staining at low magnification). The proportion of stained cells was scored as follows: $0,0 \% ;+1,1-25 \% ;+2$, $26-50 \% ;+3,51-75 \%$; or $+4,>75 \%$. Intensity and proportion of stained cells were added for the $\mathrm{Q}$ score, which ranged from 0 to 7 (8).

FISH. Sections $(4 \mu \mathrm{m})$ were cut and incubated overnight at $65^{\circ} \mathrm{C}$. The slides were deparaffinized in xylene at RT, dehydrated in 75,85 and $100 \%$ alcohol for 5 min each at room temperature and subsequently immersed in distilled water at $90^{\circ} \mathrm{C}$ for $30 \mathrm{~min}$. The slides were then incubated for $10 \mathrm{~min}$ in $1 \mathrm{ug} / \mathrm{ml}$ of protease solution (http://www.gpmedical.com. cn/index.aspx) at $37^{\circ} \mathrm{C}$. The slides were briefly washed in sodium saline citrate ( $\mathrm{pH}$ 7.2) for $5 \mathrm{~min}$ and dehydrated in 70, 85 and $100 \%$ ethanol at RT. Subsequently, the dual color HER2/CEP17 probe (10 $\mu 1$; ZytoVision $\mathrm{GmbH})$ was applied onto each slide, a cover slip was placed and sealed with rubber cement, and then the slides were transferred to
Table I. Number of breast cancer samples tested using IHC and FISH in each age group.

\begin{tabular}{lrrrrrr}
\hline & \multicolumn{2}{c}{$\mathrm{M}, \mathrm{n}$} & & \multicolumn{2}{c}{$\mathrm{CNB}, \mathrm{n}$} \\
\cline { 2 - 3 } \cline { 6 - 7 } Age of paraffin blocks, years & IHC & FISH & & IHC & FISH \\
\hline 10 & 7 & 7 & & 6 & 4 \\
7 & 9 & 9 & & 8 & 8 \\
5 & 10 & 7 & & 10 & 9 \\
3 & 10 & 10 & & 10 & 9 \\
1 & 10 & 9 & & 10 & 10 \\
\hline
\end{tabular}

IHC, immunohistochemistry; FISH, fluorescence in situ hybridization; M, mastectomy samples; CNB, core needle biopsy samples.

a hybridization oven (S500-24; Abbott Laboratories). The procedure was as follows: Denaturation at $75^{\circ} \mathrm{C}$ for $10 \mathrm{~min}$ with hybridization overnight at $37^{\circ} \mathrm{C}$. After that, the slides were washed three times for $5 \mathrm{~min}$ in $37^{\circ} \mathrm{C}$ wash buffer (ZytoVision $\mathrm{GmbH}$ ) and rinsed in $70 \%$ ethanol. After air-drying, the slides were counterstained with $15 \mu \mathrm{l}$ DAPI and a cover slip was applied. A total of 30 randomly selected invasive tumor nuclei in each of two separate distinct microscopic areas were evaluated under a fluorescent microscope (magnification, x100 oil immersion objective; Olympus Corporation). The interpretation of FISH results was based on the 2018 ASCO/CAP guidelines (14).

Signal intensity for the FISH assay was scored utilizing a four-point system: 0 , No visible signal; 1 , weak signal barely visible; 2 , signal visible but not intense; and 3 , intense signal. This four-point scoring system was applied to HER2 and CEP17 signals in tumor cells (10).

Statistical analysis. Data were analyzed using SPSS software (version 25.0; IBM Corp). Values are expressed as mean \pm standard deviation. Comparisons among groups ( $>2$ groups) were carried out with Kruskal-Wallis and Dunn's post-hoc test. Comparisons between two groups were carried out with Wilcoxon rank sum tests or Mann-Whitney tests. $\mathrm{P}<0.05$ was considered to indicate a statistically significant difference.

\section{Results}

$E R$ and PR levels of mastectomy and core needle biopsy samples for each age group. For mastectomy samples in each age group, the difference in Q scores for ER expression levels did not change significantly between original tests and repeated tests (Table II). For core needle biopsies prepared 10 years ago, $Q$ scores decreased significantly from $6.17 \pm 0.75$ for original tests to $3.17 \pm 1.33$ for repeated tests (Table II; Fig. 1A). Regarding all the samples, Q scores for repeated tests also showed a significant decrease in the 10-year group (Table II). There was no significant difference for the change in $\mathrm{Q}$ scores for other age groups (Table II). A significant difference of Q scores for PR expression between original tests and repeated tests was also observed in the 10 year group, but not the other groups (Table III; Fig. 1B and D). 


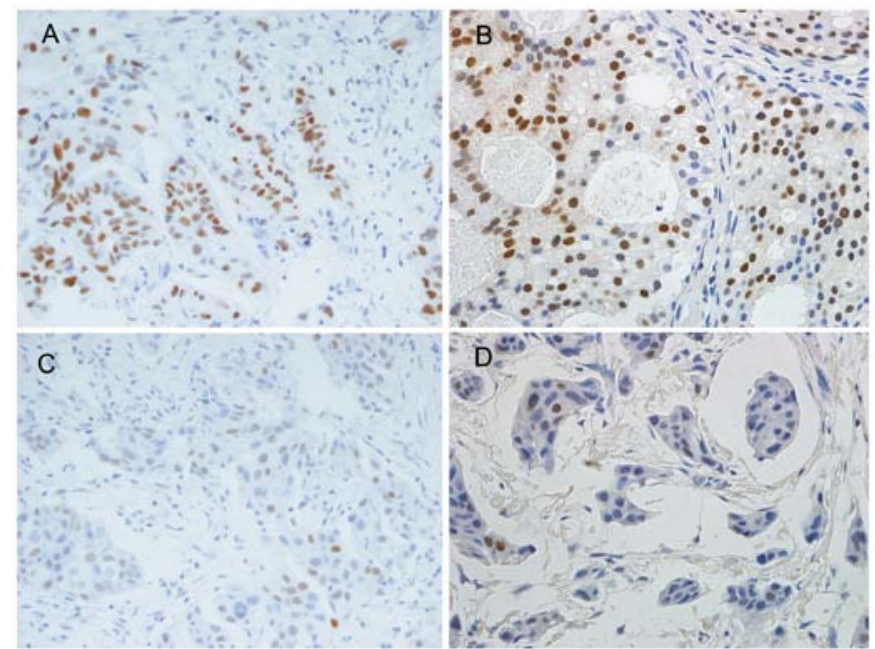

Figure 1. Immunohistochemical staining of ER and PR in core needle biopsy samples from 10 years ago. The Q score for the original test was 5 for (A) ER and (B) 5 for PR. The Q score for the repeated test was 2 for (C) ER and 2 for (D) PR. Magnification, x400. ER, estrogen receptor; PR, progesterone receptor.

Signal intensity of HER2 and CEP17 in mastectomy and core needle biopsy samples for each age group. For samples from 10 and 7 years ago, no signal for HER 2 or CEP17 could be detected for core needle biopsy samples (Tables IV and V; Fig. 2A). HER2 was detected in 5/7 and 7/9 mastectomy samples for these two age groups, respectively. Except for two samples from 7 years ago, CEP17 hybridization failed (Table V). For the remaining age groups, all samples were successfully hybridized.

The signal intensity decreased with the age of the paraffin blocks (Tables IV and V; Fig. 2A and B). Regarding HER2, the signal intensity demonstrated no significant difference between mastectomy and core needle biopsy samples in each age group, except the 3-year group (Table IV). Regarding CEP17, a significant difference was observed in the signal intensity for mastectomy and core needle biopsy samples from 5 years ago, $1.86 \pm 0.38$ and $1.22 \pm 0.67$, respectively (Table V). HER2 status did not change for the repeated samples compared with the original samples.

Signal intensity comparisons for HER 2 and CEP17 betweeneach age groups. Core needle biopsy samples from 10 and 7 years ago were not compared because HER 2 and CEP17 signals were not detected. The signal intensities for HER 2 and CEP17 for all samples in the 1 year group were the strongest compared with the samples from other age groups, with a score of $2.47 \pm 0.77$ for HER 2 and $2.32 \pm 0.82$ for CEP17, followed by samples from 3,5 , 7 and 10 years ago (Tables IV and V).

When only mastectomy samples were considered, the signal intensities of HER2 and CEP17 were stronger in samples from 1,3 and 5 years ago compared with samples from 10 and 7 years ago $(\mathrm{P}<0.05)$. No difference in signal intensity was observed for any two groups within the last 5 years. With regard to core needle biopsy samples, the signal intensities for HER 2 and CEP17 decreased significantly with the age of the paraffin blocks (Tables IV and V). 

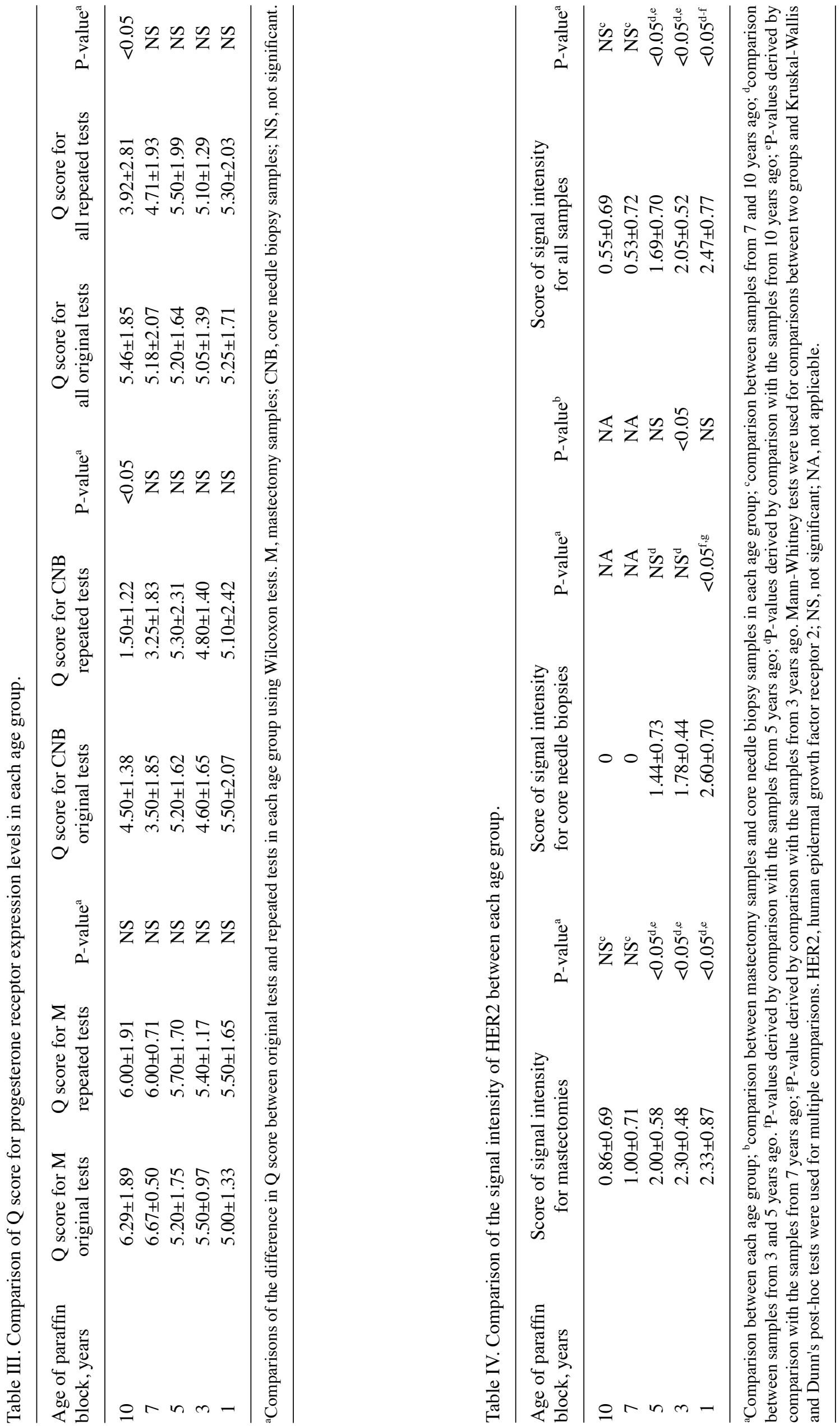

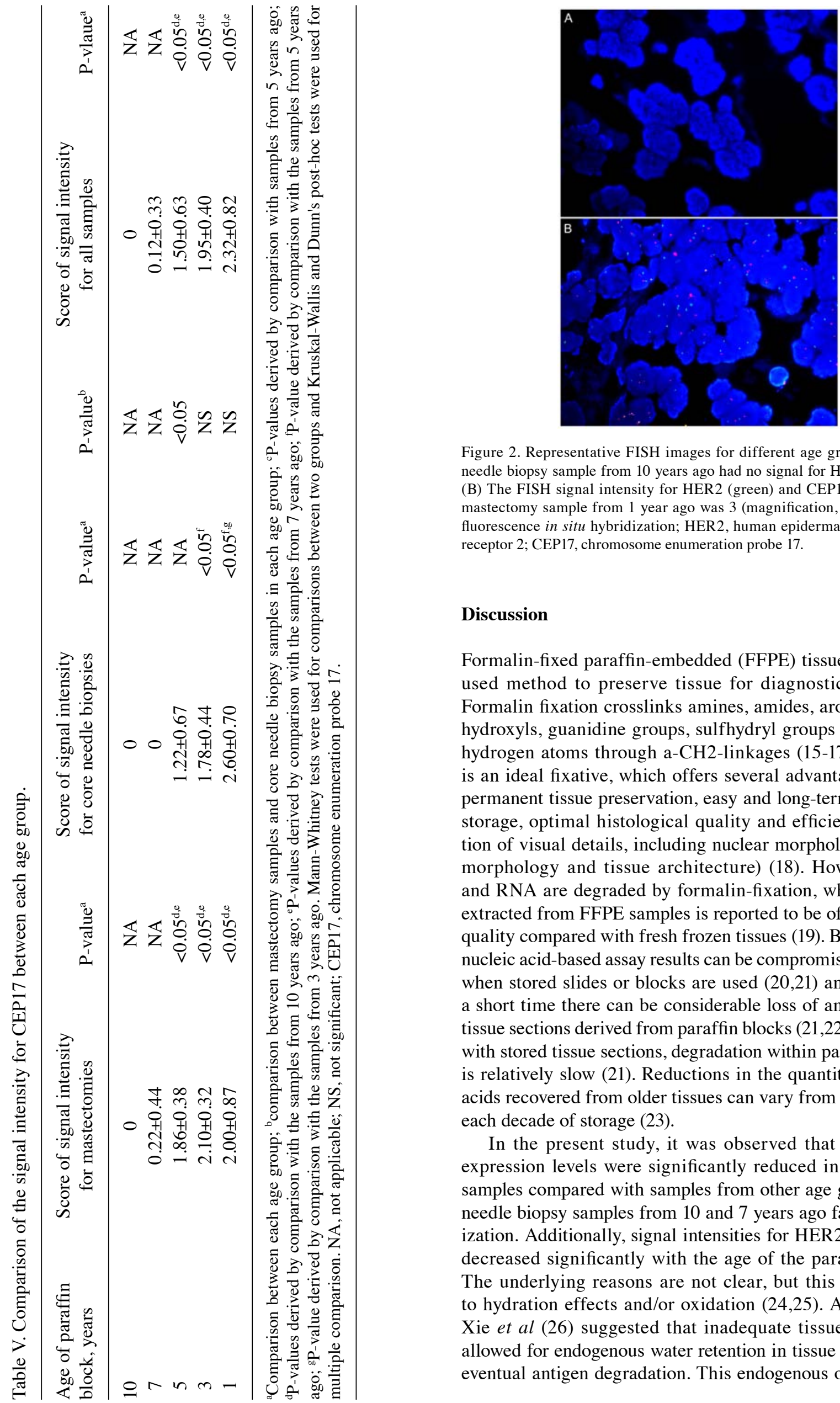

Figure 2. Representative FISH images for different age groups. (A) Core needle biopsy sample from 10 years ago had no signal for HER2 or CEP17. (B) The FISH signal intensity for HER2 (green) and CEP17 (orange) in a mastectomy sample from 1 year ago was 3 (magnification, x1,000). FISH, fluorescence in situ hybridization; HER2, human epidermal growth factor receptor 2; CEP17, chromosome enumeration probe 17.

\section{Discussion}

Formalin-fixed paraffin-embedded (FFPE) tissue is a widely used method to preserve tissue for diagnostic pathology. Formalin fixation crosslinks amines, amides, aromatic rings, hydroxyls, guanidine groups, sulfhydryl groups and reactive hydrogen atoms through a-CH2-linkages (15-17). Formalin is an ideal fixative, which offers several advantages such as permanent tissue preservation, easy and long-term affordable storage, optimal histological quality and efficient preservation of visual details, including nuclear morphology, cellular morphology and tissue architecture) (18). However, DNA and RNA are degraded by formalin-fixation, whereby RNA extracted from FFPE samples is reported to be of much lower quality compared with fresh frozen tissues (19). Both IHC and nucleic acid-based assay results can be compromised over time when stored slides or blocks are used $(20,21)$ and even after a short time there can be considerable loss of antigenicity in tissue sections derived from paraffin blocks $(21,22)$. Compared with stored tissue sections, degradation within paraffin blocks is relatively slow (21). Reductions in the quantity of nucleic acids recovered from older tissues can vary from 5 to $50 \%$ for each decade of storage (23).

In the present study, it was observed that ER and PR expression levels were significantly reduced in 10-year old samples compared with samples from other age groups. Core needle biopsy samples from 10 and 7 years ago failed hybridization. Additionally, signal intensities for HER2 and CEP17 decreased significantly with the age of the paraffin blocks. The underlying reasons are not clear, but this may be due to hydration effects and/or oxidation $(24,25)$. Alternatively, Xie et al (26) suggested that inadequate tissue processing allowed for endogenous water retention in tissue sections and eventual antigen degradation. This endogenous or exogenous 
Table VI. Cases showing a negative shift of Q score for PR and ER expression levels.

\begin{tabular}{ccccc}
\hline Age of paraffin blocks, years & Specimen type & Biomarkers & Q score from original tests & Q score from repeated tests \\
\hline 10 & CNB & PR & 6 & 0 \\
10 & CNB & PR & 2 & 0 \\
7 & CNB & PR & 2 & 0 \\
5 & CNB & PR & 2 & 0 \\
1 & CNB & PR & 2 & 0 \\
1 & CNB & ER & 2 & 0 \\
\hline
\end{tabular}

CNB, core needle biopsy samples; PR, progesterone receptor; ER, estrogen receptor.

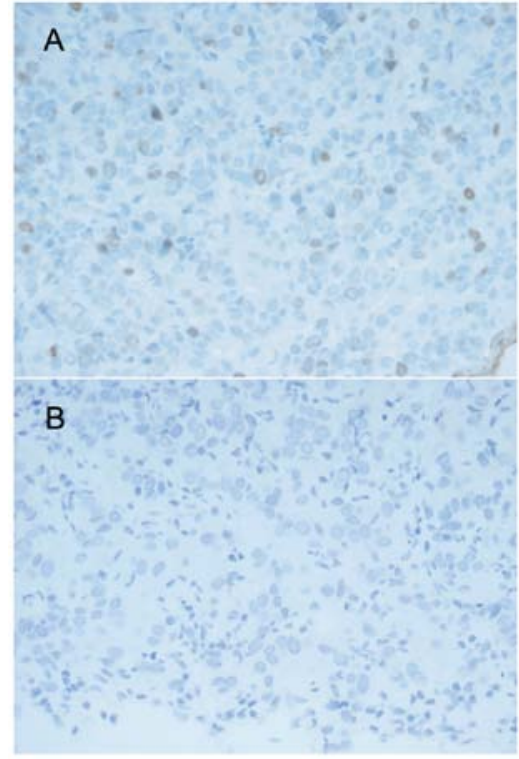

Figure 3. A core needle biopsy sample from 1 year ago showing a negative shift in Q score for PR. (A) Q score for the original test was 2. (B) Q score for the repeated test was 0 . Magnification, $\mathrm{x} 400$. PR, progesterone receptor.

water may explain why some methods of preservation are ineffective, including cold storage of slides at $4^{\circ} \mathrm{C}(27)$, paraffin coating (28) or storage of slides in a nitrogen desiccator (29). Optimal tissue processing is of particular importance, as if tissues are efficiently fixed, processed and stored, antigen degradation occurs at a slower rate in paraffin blocks $(26,30)$.

The Q scores for ER and PR expression levels, and the signal intensities of HER2 and CEP17 in mastectomy and core needle biopsy samples from tissue blocks, derived from five different block age groups, were compared. No HER2 or CEP17 signals could be detected in core needle biopsy samples $>7$ years of age; however, HER 2 signals were detected in the majority of mastectomy samples in the 10 year group. Q scores for ER and PR expression levels of core needle biopsy samples from 10 years ago were decreased significantly. However, for the mastectomy samples in each age group, the difference in Q scores for ER and PR expression levels were not significantly different between original tests and repeated tests. Moreover, 6/7 mastectomy samples from 10 years ago showed no change in Q score for PR expression levels. Based on these results, mastectomy samples as old as
10 years yielded excellent PR results. Thus, in addition to variability in tissue processing, the storage time of paraffin blocks may be a factor affecting the differences between mastectomy and core needle biopsy samples; however, the basis for this difference is unknown.

False-negative breast biomarkers are a serious issue as these biomarkers determine both endocrine and targeted therapies. False negative results can be due to sampling error, delay in exposure to formalin, incorrect concentration of the antibody/probe, incorrect pretreatment, incorrect calibration of the automated platform, inherent variability in the interpretation of results and variability of the signal in a given lesion $(8,12,31-34)$. In the present study, six core needle biopsy cases were identified as having a Q score of 0 following repeated tests, of which five had Q scores of 6, 2, 2, 2 and 2 for PR expression, while one had a Q score of 2 for ER expression, from the original tests (Table VI; Fig. 3). These cases associated with PR levels for core needle biopsy samples that scored 2 (Table VI; Fig. 3). This may be associated with the occurrence of false-negatives. As such, closer attention to the interpretation of PR results for repeated tests is needed for core needle biopsy samples with Q score of 2 .

A significant limitation of the present study was the small number of patients, limiting the ability to determine the influence of paraffin block age on biomarker expression levels in archival breast cancer samples. The major reason for the small sample size was that very few cases were referred for FISH testing in the Department of Pathology, The First Affiliated Hospital of Zhejiang University (Hangzhou, China) for almost 6 years after FISH testing was introduced in 2007. A larger cohort should be included in any future study to warrant the reliability of the findings from the present study.

In conclusion, the age of paraffin blocks has a significant effect on ER and PR expression levels in core needle biopsy samples. The expression levels of ER and PR were considerably reduced in core needle biopsy samples from 10 years ago. Moreover, samples from $>7$ years ago were not suitable for FISH analysis. Furthermore, caution should be exercised for repeat interpretation of PR expression levels for core needle biopsy samples with a $\mathrm{Q}$ score of 2 .

\section{Acknowledgements}

The authors would like to thank Mr. Liming Xu, Mr. Jian Dong and Mr. Jinlong Cui for their assistance with immunohisto- 
chemistry staining, and Miss Yanfeng Bai for her assistance in histological analysis [all from the Department of Pathology, The First Affiliated Hospital of the College of Medicine, Zhejiang University (Hangzhou, China)].

\section{Funding}

No funding was received.

\section{Availability of data and materials}

All data generated and/or analyzed during the present study are included in this published article.

\section{Authors' contributions}

BW designed the study, performed the experiments and analyzed the data. HC and QQF collected and analyzed the data and wrote the manuscript. All authors read and approved the final version of the manuscript.

\section{Ethics approval and consent to participate}

The present study was approved by The Ethics Committee of the First Affiliated Hospital, College of Medicine, Zhejiang University (Hangzhou, China; approval no. 20181096). The Committee waived the need for informed consent from the patients, since the study was completed anonymously.

\section{Patient consent for publication}

Not applicable.

\section{Competing interests}

The authors declare that they have no competing interests.

\section{References}

1. Jemal A, Bray F, Center MM, Ferlay J, Ward E and Forman D: Global cancer statistics. CA Cancer J Clin 61: 69-90, 2011.

2. Yildiz-Aktas IZ, Dabbs DJ and Bhargava R: The effect of cold ischemic time on the immunohistochemical evaluation of estrogen receptor, progesterone receptor, and HER2 expression in invasive breast carcinoma. Mod Pathol 25 1098-1105, 2012.

3. Barnes DM, Millis RR, Beex LV, Thorpe SM and Leake RE: Increased use of immunohistochemistry for oestrogen receptor measurement in mammary carcinoma: The need for quality assurance. Eur J Cancer 34: 1677-1682, 1998.

4. Harris L, Fritsche H, Mennel R, Norton L, Ravdin P, Taube S, Somerfield MR, Hayes DF and Bast RC Jr; American Society of Clinical Oncology: American Society of Clinical Oncology 2007 update of recommendations for the use of tumor markers in breast cancer. J Clin Oncol 25: 5287-5312, 2007.

5. Dowsett M, Allred C, Knox J, Quinn E, Salter J, Wale C, Cuzick J, Houghton J, Williams N, Mallon E, et al: Relationship between quantitative estrogen and progesterone receptor expression and human epidermal growth factor receptor 2 (HER-2) status with recurrence in the Arimidex, Tamoxifen, Alone or in Combination trial. J Clin Oncol 26: 1059-1065, 2008.

6. Rhodes A, Jasani B, Balaton AJ, Barnes DM and Miller KD: Frequency of oestrogen and progesterone receptor positivity by immunohistochemical analysis in 7016 breast carcinomas: Correlation with patient age, assay sensitivity, threshold value, and mammographic screening. J Clin Pathol 53: 688-696, 2000 .
7. Wolff AC, Hammond ME, Schwartz JN, Hagerty KL, Allred DC, Cote RJ, Dowsett M, Fitzgibbons PL, Hanna WM, Langer A, et al; American Society of Clinical Oncology; College of American Pathologists: American Society of Clinical Oncology/College of American Pathologists guideline recommendations for human epidermal growth factor receptor 2 testing in breast cancer. J Clin Oncol 25: 118-145, 2007.

8. Khoury T, Sait S, Hwang H, Chandrasekhar R, Wilding G, Tan D and Kulkarni S: Delay to formalin fixation effect on breast biomarkers. Mod Pathol 22: 1457-1467, 2009.

9. Moatamed NA, Nanjangud G, Pucci R, Lowe A, Shintaku IP, Shapourifar-Tehrani S, Rao N, Lu DY and Apple SK: Effect of ischemic time, fixation time, and fixative type on HER2/neu immunohistochemical and fluorescence in situ hybridization results in breast cancer. Am J Clin Pathol 136: 754-761, 2011.

10. Portier BP, Wang Z, Downs-Kelly E, Rowe JJ, Patil D, Lanigan C, Budd GT, Hicks DG, Rimm DL and Tubbs RR: Delay to formalin fixation 'cold ischemia time': Effect on ERBB2 detection by in-situ hybridization and immunohistochemistry. Mod Pathol 26: $1-9,2013$.

11. Reddy JC, Reimann JD, Anderson SM and Klein PM: Concordance between central and local laboratory HER2 testing from a community-based clinical study. Clin Breast Cancer 7: 153-157, 2006.

12. Nuovo AJ, Garofalo M, Mikhail A, Nicol AF, Vianna-Andrade C and Nuovo GJ: The effect of aging of formalin-fixed paraffin-embedded tissues on the in situ hybridization and immunohistochemistry signals in cervical lesions. Diagn Mol Pathol 22: 164-173, 2013.

13. Goldstein NS, Ferkowicz M, Odish E, Mani A and Hastah F: Minimum formalin fixation time for consistent estrogen receptor immunohistochemical staining of invasive breast carcinoma. Am J Clin Pathol 120: 86-92, 2003.

14. Wolff AC, Hammond MEH, Allison KH, Harvey BE, Mangu PB, Bartlett JMS, Bilous M, Ellis IO, Fitzgibbons P, Hanna W, et al: Human Epidermal Growth Factor Receptor 2 Testing in Breast Cancer: American Society of Clinical Oncology/College of American Pathologists Clinical Practice Guideline Focused Update. J Clin Oncol 36: 2105-2122, 2018.

15. Moelans CB, Oostenrijk D, Moons MJ and van Diest PJ: Formaldehyde substitute fixatives: Effects on nucleic acid preservation. J Clin Pathol 64: 960-967, 2011.

16. Dapson RW: Glyoxal fixation: How it works and why it only occasionally needs antigen retrieval. Biotech Histochem 82: 161-166, 2007.

17. Dapson RW: Macromolecular changes caused by formalin fixation and antigen retrieval. Biotech Histochem 82: 133-140, 2007.

18. Perlmutter MA, Best CJM, Gillespie JW, Gathright Y, González S, Velasco A, Linehan WM, Emmert-Buck MR and Chuaqui RF: Comparison of snap freezing versus ethanol fixation for gene expression profiling of tissue specimens. J Mol Diagn 6: 371-377, 2004.

19. Scicchitano MS, Dalmas DA, Bertiaux MA, Anderson SM, Turner LR, Thomas RA, Mirable R and Boyce RW: Preliminary comparison of quantity, quality, and microarray performance of RNA extracted from formalin-fixed, paraffin-embedded, and unfixed frozen tissue samples. J Histochem Cytochem 54: 1229-1237, 2006.

20. Nirmalan NJ, Harnden P, Selby PJ and Banks RE: Development and validation of a novel protein extraction methodology for quantitation of protein expression in formalin-fixed paraffin-embedded tissues using western blotting. J Pathol 217: 497-506, 2009.

21. Hewitt SM, Lewis FA, Cao Y, Conrad RC, Cronin M, Danenberg KD, Goralski TJ, Langmore JP, Raja RG, Williams PM, et al: Tissue handling and specimen preparation in surgical pathology: Issues concerning the recovery of nucleic acids from formalin-fixed, paraffin-embedded tissue. Arch Pathol Lab Med 132: 1929-1935, 2008.

22. Chung JY, Braunschweig T, Williams R, Guerrero N, Hoffmann KM, Kwon M, Song YK, Libutti SK and Hewitt SM: Factors in tissue handling and processing that impact RNA obtained from formalin-fixed, paraffin-embedded tissue. J Histochem Cytochem 56: 1033-1042, 2008.

23. Cronin M, Pho M, Dutta D, Stephans JC, Shak S, Kiefer MC, Esteban JM and Baker JB: Measurement of gene expression in archival paraffin-embedded tissues: Development and performance of a 92-gene reverse transcriptase-polymerase chain reaction assay. Am J Pathol 164: 35-42, 2004. 
24. Fergenbaum JH, Garcia-Closas M, Hewitt SM, Lissowska J Sakoda LC and Sherman ME: Loss of antigenicity in stored sections of breast cancer tissue microarrays. Cancer Epidemiol Biomarkers Prev 13: 667-672, 2004.

25. Wester K, Wahlund E, Sundström C, Ranefall P, Bengtsson E, Russell PJ, Ow KT, Malmström PU and Busch C: Paraffin section storage and immunohistochemistry. Effects of time, temperature fixation, and retrieval protocol with emphasis on p53 protein and MIB1 antigen. Appl Immunohistochem Mol Morphol 8: 61-70, 2000.

26. Xie R, Chung JY, Ylaya K, Williams RL, Guerrero N, Nakatsuka N, Badie C and Hewitt SM: Factors influencing the degradation of archival formalin-fixed paraffin-embedded tissue sections. J Histochem Cytochem 59: 356-365, 2011.

27. van den Broek LJ and van de Vijver MJ: Assessment of problems in diagnostic and research immunohistochemistry associated with epitope instability in stored paraffin sections. Appl Immunohistochem Mol Morphol 8: 316-321, 2000.

28. Jacobs TW, Prioleau JE, Stillman IE and Schnitt SJ: Loss of tumor marker-immunostaining intensity on stored paraffin slides of breast cancer. J Natl Cancer Inst 88: 1054-1059, 1996.

29. DiVito KA, Charette LA, Rimm DL and Camp RL: Long-term preservation of antigenicity on tissue microarrays. Lab Invest 84 1071-1078, 2004.

30. Mirlacher M, Kasper M, Storz M, Knecht Y, Dürmüller U, Simon R, Mihatsch MJ and Sauter G: Influence of slide aging on results of translational research studies using immunohistochemistry. Mod Pathol 17: 1414-1420, 2004.
31. Stoler MH: Toward objective cervical cancer screening: Maybe the eyes do have it. Am J Clin Pathol 134: 5-6, 2010.

32. Copete M, Garratt J, Gilks B, Pilavdzic D, Berendt R, Bigras G, Mitchell S, Lining LA, Cheung C and Torlakovic EE: Inappropriate calibration and optimisation of pan-keratin (pan-CK) and low molecular weight keratin (LMWCK) immunohistochemistry tests: Canadian Immunohistochemistry Quality Control (CIQC) experience. J Clin Pathol 64: 220-225, 2011.

33. Denton KJ, Bergeron C, Klement P, Trunk MJ, Keller T and Ridder R; European CINtec Cytology Study Group: The sensitivity and specificity of p16(INK4a) cytology vs HPV testing for detecting high-grade cervical disease in the triage of ASC-US and LSIL pap cytology results. Am J Clin Pathol 134: 12-21, 2010.

34. Hammond ME, Hayes DF, Dowsett M, Allred DC, Hagerty KL, Badve S, Fitzgibbons PL, Francis G, Goldstein NS, Hayes M, et al: American Society of Clinical Oncology/College of American Pathologists guideline recommendations for immunohistochemical testing of estrogen and progesterone receptors in breast cancer (Unabridged Version). Arch Pathol Lab Med 134: e48-e72, 2010.

This work is licensed under a Creative Commons Attribution-NonCommercial-NoDerivatives 4.0 International (CC BY-NC-ND 4.0) License. 